\title{
Soluble ST2 and mixed venous oxygen saturation for prediction of mortality in patients with pulmonary hypertension
}

\author{
Yuanyuan Sun ${ }^{1}$, Lan Wang ${ }^{1}$, Xiangrui Meng ${ }^{2}$, Sugang Gong ${ }^{1}$, Qinhua Zhao ${ }^{1}$, Lingzi Shi ${ }^{3}$, Rong Jiang ${ }^{1}$, \\ Jing $\mathrm{He}^{1}$, Wenhui $\mathrm{Wu}^{1}$, Yuan $\mathrm{Li}^{1}$, Cijun Luo ${ }^{1}$, Hongling Qiu ${ }^{1}$, Jinling $\mathrm{Li}^{1}$, Ping Yuan ${ }^{1}$, Jinming Liu ${ }^{1}$ \\ ${ }^{1}$ Department of Cardio-Pulmonary Circulation, Shanghai Pulmonary Hospital, Tongji University, School of Medicine, Shanghai, China; ${ }^{2}$ Institute \\ of Bismuth Science, University of Shanghai for Science and Technology, Shanghai, China; ${ }^{3}$ School of Clinical Medicine, Hebei Medical University, \\ Shijiazhuang, China \\ Contributions: (I) Conception and design: P Yuan, J Liu; (II) Administrative support: S Gong, Q Zhao; (III) Provision of study materials or patients: L \\ Wang, L Shi, R Jiang, J He, W Wu, Y Li, C Luo, H Qiu, J Li; (IV) Collection and assembly of data: Y Sun; (V) Data analysis and interpretation: Y \\ Sun, L Wang, X Meng; (VI) Manuscript writing: All authors; (VII) Final approval of manuscript: All authors. \\ Correspondence to: Jinming Liu, MD; Ping Yuan, MD. Department of Cardio-Pulmonary Circulation Shanghai Pulmonary Hospital Affiliated to \\ Tongji University, No. 507 Zhengmin Road, Shanghai, 200433, China. Email: jinmingliu@tongji.edu.cn and pandyyuan@tongji.edu.cn.
}

\begin{abstract}
Background: Although soluble suppression of tumorigenicity-2 (sST2) has been identified as a clinical biomarker for pulmonary hypertension (PH) by previous studies, the implication of sST2 combined with hemodynamic parameters in PH has not been well studied. This study aimed to evaluate the relationship between sST2 and hemodynamic parameters and to evaluate the predictive value of sST2 for mortality in patients with $\mathrm{PH}$.

Methods: One hundred eighty-four incident patients with $\mathrm{PH}$ and 14 healthy controls were retrospectively enrolled by Shanghai Pulmonary Hospital for this retrospective study. After all patients underwent right heart catheterization, blood samples were collected and serum sST2 concentration was assessed by the Presage $^{\text {TM }}$ ST2 assay. Kaplan-Meier curve and Cox regression analyses were used to predict survival and the association between survival and different factors such as $\mathrm{SST} 2, \mathrm{SvO}_{2}$.

Results: During a follow-up of 44.9 (IQR 28.5-64.4) months, 65 patients died. The median concentration of sST2 in PH patients was $33.1 \mathrm{ng} / \mathrm{mL}$, which is higher than that in control group $(23.1 \mathrm{ng} / \mathrm{mL}, \mathrm{P}=0.005)$. Furthermore, for PH group, the level of sST2 was higher in non-survivors than that in survivors. Cox regression analyses demonstrated that $\mathrm{SST} 2$ and $\mathrm{SvO}_{2}$ were independent risk factors for survival. In KaplanMeier curve analyses, elevated sST2 level and reduced $\mathrm{SvO}_{2}$ predicted a poor outcome for patients with PH. Conclusions: Higher sST2 was independently associated with increased mortality, as well as lower $\mathrm{SvO}_{2}$ in patients with PH. Especially, the combination of higher sST2 and lower $\mathrm{SvO}_{2}$ had the strongest predictive value of mortality in patients with $\mathrm{PH}$.
\end{abstract}

Keywords: Pulmonary hypertension (PH); soluble suppression of tumorigenicity-2; mixed venous oxygen saturation; prognosis

Submitted Aug 29, 2020. Accepted for publication Apr 29, 2021.

doi: $10.21037 /$ jtd-20-2732

View this article at: http://dx.doi.org/10.21037/jtd-20-2732

\section{Introduction}

Right ventricular dysfunction is one of the major complications in patients suffered from pulmonary hypertension $(\mathrm{PH})$. Elevated pulmonary arterial pressures, induced by an increased pulmonary vascular resistance (PVR), can lead to progressive right ventricular failure over time (1), contributing to a significant poor prognosis (2-4). Predicting the severity of pulmonary vascular 
remodeling, the cardiac function, and outcomes in $\mathrm{PH}$ is essential though challenging. Many baselines or followup parameters, including clinical features (clinical signs of right heart failure, progression of symptoms, syncope), World Health Organization functional class (WHO-FC), 6-minute walking distance $(6 \mathrm{MWD})$, cardiopulmonary exercise testing (CPET), biomarkers (N-terminal probrain natriuretic peptide (NT-proBNP) and certain variables derived from echocardiography and right heart catheterization (RHC) (5-8), have a role in evaluating the prognosis of $\mathrm{PH}$. In daily clinical practice, very limited number of biomarkers can be identified to assess $\mathrm{PH}$ severity. NT-proBNP is a recommended biomarker for evaluating cardiac function and has been proved to be helpful in assessing risk stratification in $\mathrm{PH}$ (5). However, it is greatly affected by renal function, limiting its clinical application (9-12). Therefore, the validation of new biomarkers is of great clinical significance.

Recently, a new biomarker, suppression of tumorigenicity-2 (ST2), has been well investigated for its role to evaluate heart function. ST2 is an interleukin-1 (IL-1) receptor family member that exists in both transmembrane (ST2L) and soluble ST2 (sST2) isoforms. On the one hand, ST2L is a receptor for interleukin-33 (IL-33) and has been found to play a cardioprotective role in experimental models (13). By binding to ST2L, IL-33 exerts the effects such as reducing myocardial fibrosis, cardiomyocyte hypertrophy and apoptosis, as well as improving myocardial function (14). On the other hand, sST2 can be upregulated since cardiomyocytes and fibroblasts respond to mechanical stimulation or injury $(15,16)$. The upregulated sST2 avidly binds to IL-33, resulting in an interruption of the interaction between IL-33 and ST2L, and consequently eliminating the anti-remodeling effects $(15,16)$. Therefore, sST2 has been nominated as a promising biomarker in heart failure population $(17,18)$. Previously, a study indicated that the circulating ligand of sST2, IL-33 might play a pivotal role in vascular remodeling of pulmonary endothelium in idiopathic pulmonary arterial hypertension (IPAH) patients (19). Moreover, sST2 has been shown to be correlated with right ventricular dysfunction in pulmonary arterial hypertension (PAH) patients (20). However, sST2 has not been reported in other classifications of $\mathrm{PH}$. As sST2 may reflect both cardiac as well as pulmonary vascular remodeling, it could be a potential biomarker to monitor the deterioration of $\mathrm{PH}$ in the clinical practice. Furthermore, although the hemodynamic parameters have been demonstrated to play an indispensable role in assessing the prognosis of $\mathrm{PH}(2)$, the joint use of them with sST2 in PH has not been studied.
By measuring the sST2 levels in various $\mathrm{PH}$ classifications, this study aimed to study the relations between sST2 and hemodynamic parameters, and to evaluate the predictive value of sST2 for mortality in patients with $\mathrm{PH}$.

We present the following article in accordance with the STROBE reporting checklist (available at http://dx.doi. org/10.21037/jtd-20-2732).

\section{Methods}

\section{Study population}

From February 2007 to September 2018, 184 incident patients with $\mathrm{PH}$ (mean age was $51.4 \pm 18.5$ years, $54.3 \%$ woman) and 14 healthy (mean age was $50.2 \pm 17.9$ years, $51.3 \%$ woman) control patients were retrospectively enrolled by Shanghai Pulmonary Hospital. In particular, the subjects selected for this study were only patients with IPAH $(n=106)$, chronic obstructive pulmonary disease-pulmonary hypertension (COPD-PH) ( $\mathrm{n}=64)$, and chronic thromboembolic pulmonary hypertension (CTEPH) ( $\mathrm{n}=14)$. Diagnosis of $\mathrm{PH}$ was defined by the mean level of PAP (mPAP) ( $\geq 25 \mathrm{mmHg}$ ), measured by RHC in accordance with the European Society of Cardiology (ESC) guidelines (2). The candidates were excluded according to the criteria as follows: the ones unconfirmed diagnosis of $\mathrm{PH}$ due to incomplete diagnostic work-up, the ones without treatment-naïve or incapable of understanding and signing informed consent. Additionally, the patients with other classifications of $\mathrm{PH}$ were also excluded.

This study conformed to the provisions of the Declaration of Helsinki (as revised in 2013). The study was approved by the Ethics committees of Shanghai Pulmonary Hospital (K20-195Y). All patients have submitted informed consents.

\section{RHC assessment}

Hemodynamic parameters were collected at baseline. An 8-F introducer sheath was placed in the right or left internal jugular vein, through which a Swan-Ganz thermodilution catheter (Edwards Lifesciences, Irvine, CA, USA) was introduced. Then, the parameters such as cardiac output (CO) (thermodilution method), PAP, mean right atrial pressure (mRAP), pulmonary artery oxygen saturation $\left(\mathrm{PaO}_{2}\right)$ level and pulmonary artery wedge pressure (PAWP) were evaluated. The systemic and PVR were calculated using standard equations (21). Mixed-venous blood samples 
were drawn and analyzed with a blood gas analyzer (ABL 555; Radiometer, Copenhagen, Denmark).

\section{Laboratory analysis}

Venous blood samples were taken during RHC only for study purpose. And the clinical decisions were made independent of biomarkers. The level of NT-proBNP was analyzed with fresh samples in the clinical laboratory of Shanghai Pulmonary Hospital, using a chemiluminescent assay. The other of the samples were aliquoted and stored at $-80{ }^{\circ} \mathrm{C}$ until the batch analysis was conducted. Moreover, the level of sST2 was measured from banked serum samples via a highly sensitive sandwich monoclonal immunoassay (Presage $^{\text {TM }}$ ST2 assay, Critical Diagnostics, San Diego, CA) (22). The blood used for the present study had been previously subjected to a single freeze-thaw cycle. All the parameters were measured by the methods personnel blinded to patient clinical information.

\section{Followed-up of patients}

The primary endpoint was defined as all-cause mortality. The status of patients was checked in outpatient clinics or by phone call with half-yearly intervals. Information of all patients was retrieved from electronic patient records. Patients were censored at the end of the follow-up period (1 October 2019) if they did not meet the requirements of endpoints.

\section{Statistical analysis}

Continuous variables were presented as mean \pm standard deviation (SD) or medians (interquartile range) and categorical variables were presented as percentage number (\%). For comparing clinical characteristics of patients, chi-square tests were used for the analysis of categorical data and the Student's $t$-test or Mann-Whitney $U$ test were performed for analyzing continuous data. Spearman correlation coefficient was used to describe correlations between sST2 and baseline characteristics and the correlations were visualized with scatterplots and correlation matrix. Moreover, the impact of parameters on prognosis was evaluated using univariate cox proportional hazards analyses, variables that achieved significance at $\mathrm{P}<0.05$ were entered into the multivariable analyses. Factors such as age, body surface area (BSA) and gender were added in models to adjust the multivariate analysis for obtaining more accurate results. To investigate the sensitivity and specificity of sST2, the area under the receiver operating characteristic curves was performed. The optimal cut-off value of sST2 was determined by Youden index. Survival curves were derived using the Kaplan-Meier method and were then compared with the log-rank test.

All statistical tests were two-tailed, the statistical significance level of $\mathrm{P}<0.05$ was used. Statistical analysis was determined with SPSS (Statistic Package for Social Science, Chicago, IL, USA) version 25.0, GraphPad Prism (San Diego, CA, USA) version 8.0 and $\mathrm{R}$ version 3.5.0 (http:// www.r-project.org/).

\section{Results}

\section{Baseline characteristics}

The Clinical characteristics, hemodynamics, echocardiography, laboratory results and specific therapy at baseline were shown in Table 1. In this analysis, 184 patients (mean age of $51.4 \pm 18.5$ years, $54.3 \%$ female) with $\mathrm{PH}$ were enrolled as subjects, including 106 (57.6\%) with IPAH, 64 (34.7\%) with COPD-PH and 14 (7.6\%) with CTEPH. And among all subjects, $117(63.5 \%)$ patients could be classified into class III/IV according to the WHO-FC.

On the other hand, there was not significant differences in the $\mathrm{PH}$ subgroups in regarding of WHO-FC, pulmonary artery pulsatility index (PAPi), left ventricular end diastolic dimension (LVEDD), left ventricular ejection fraction (LVEF) and sST2. However, there was a significant difference between IPAH group and COPD-PH group in terms of age, sex, BSA, 6MWD, NT-proBNP, mRAP, mPAP, mPAWP, PVR, CO, mixed venous oxygen saturation $\left(\mathrm{SvO}_{2}\right), \mathrm{PaO}_{2}, \mathrm{RAP} / \mathrm{PAWP}$, right ventricular stroke work index (RVSWI), right atrial (RA) area and trans annular plain systolic excursion (TAPSE). Target medications including phosphodiesterase type 5 inhibitors (sildenail, tadalafil and vadenafil), oral endothelial receptor antagonists (ambrisentan and bosentan) and soluble guanylate cyclase stimulator (riociguat) as well as combination therapy and nonspecific medications were used by patients in the present study. There were no apparent differences in the use of medications between the survival and non-survival groups.

\section{Concentrations of sST2 in different groups}

The Level of sST2 in different classifications of $\mathrm{PH}$ was presented in Figure 1. The median sST2 level was 33.1 
Table 1 Comparison of clinical characteristics as a function of survival

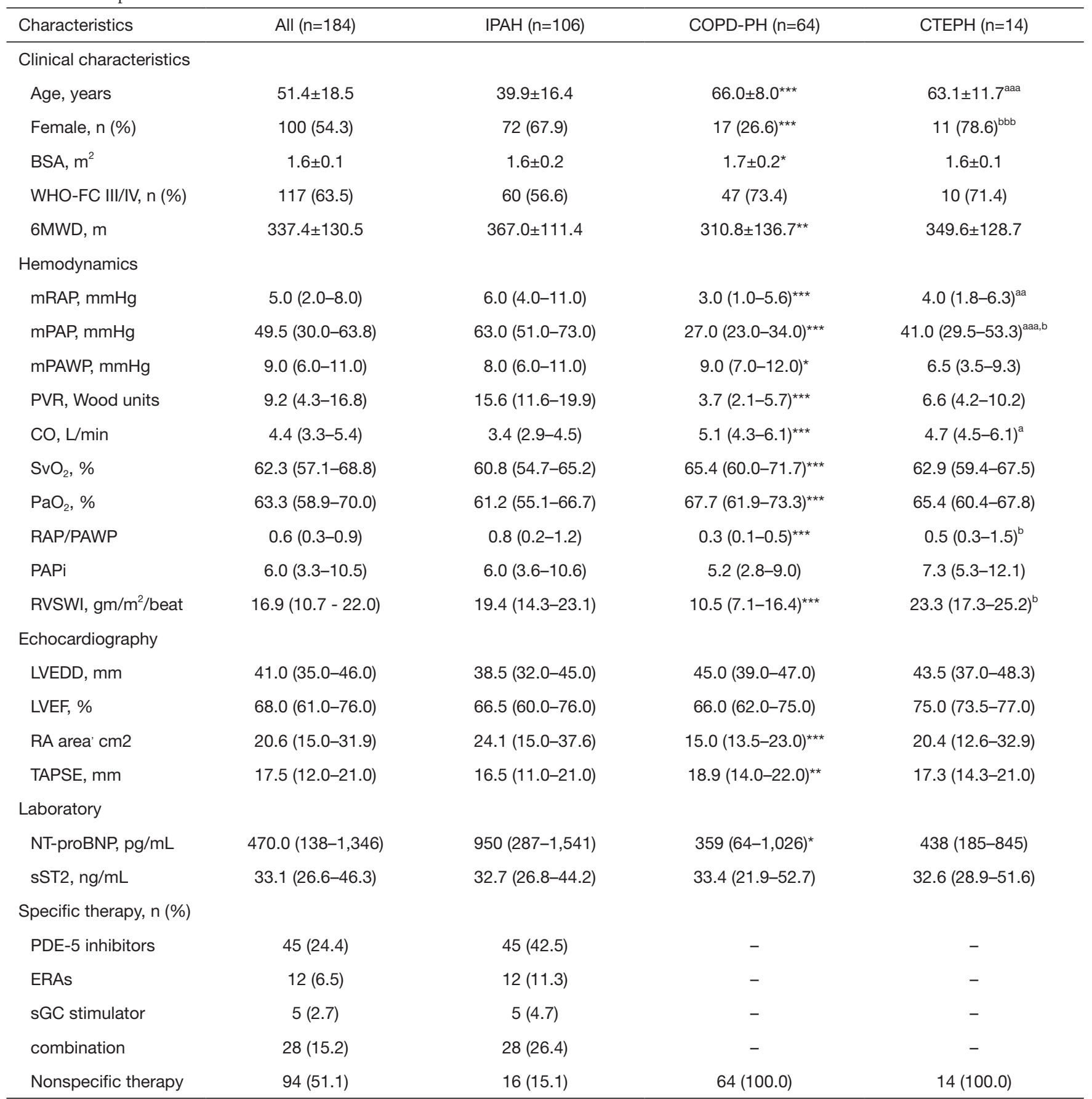

Data are presented as $\mathrm{n}(\%)$, mean $\pm \mathrm{SD}$, and interquartile range. ${ }^{\star} \mathrm{P}<0.05,{ }^{\star \star} \mathrm{P}<0.01$ and ${ }^{* \star \star} \mathrm{P}<0.0001, \mathrm{IPAH}$ vs. COPD-PH; ${ }^{\text {a }} \mathrm{P}<0.05$, ${ }^{\text {aa }} \mathrm{P}<0.01$ and ${ }^{\text {aaa }} \mathrm{P}<0.0001$, IPAH vs. CTEPH; ${ }^{b} \mathrm{P}<0.05$, ${ }^{\text {bb }} \mathrm{P}<0.01$ and ${ }^{\text {bbb }} \mathrm{P}<0.0001$, COPD-PH vs. CTEPH. 6MWD, 6-minute walking distance; BSA, body surface area; $\mathrm{CO}$, cardiac output; COPD-PH, chronic obstructive pulmonary disease-pulmonary hypertension; $\mathrm{CTEPH}$, chronic thromboembolic pulmonary hypertension; ERA, endothelin receptor antagonist; IPAH: idiopathic pulmonary arterial hypertension; LVEDD, left ventricular end diastolic dimension; LVEF, left ventricular ejection fraction; mPAP, mean pulmonary arterial pressure; mPAWP, mean pulmonary artery wedge pressure; mRAP, mean right atrial pressure; NT-proBNP, N-terminal pro-brain natriuretic peptide; $\mathrm{PaO}_{2}$, pulmonary artery oxygen saturation; PAPi, pulmonary artery pulsatility index; PDE-5, phosphodiesterase 5; PVR, pulmonacry vascular resistance; RA, right atrial; RVSWI, right ventricular stroke work index; sGC: soluble guanylate cyclase; sST2, soluble suppression of tumorigenicity-2; $\mathrm{SvO}_{2}$, mixed venous oxygen saturation; TAPSE, trans annular plain systolic excursion; WHO-FC, World Health Organization fictional classification. 
A

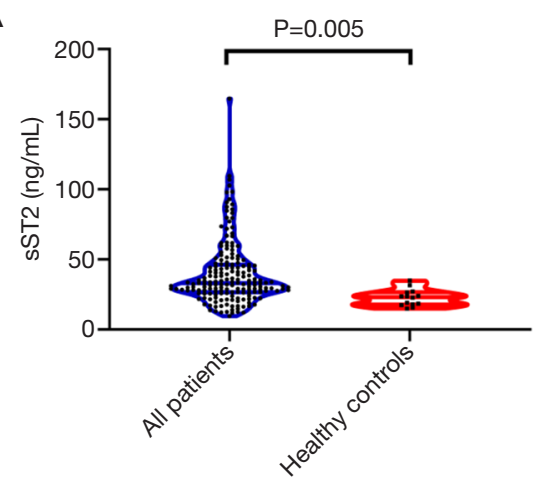

C

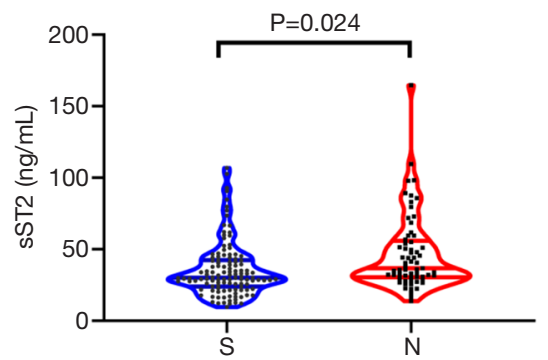

E

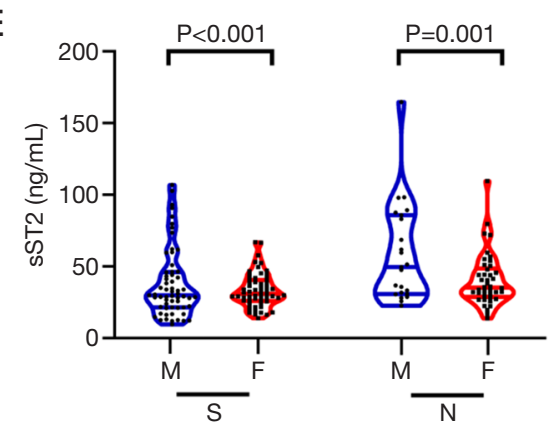

G

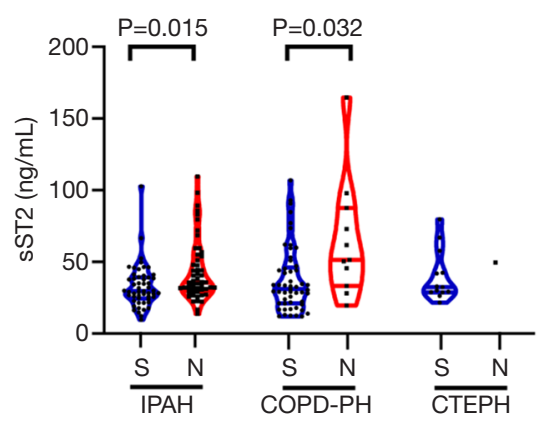

B

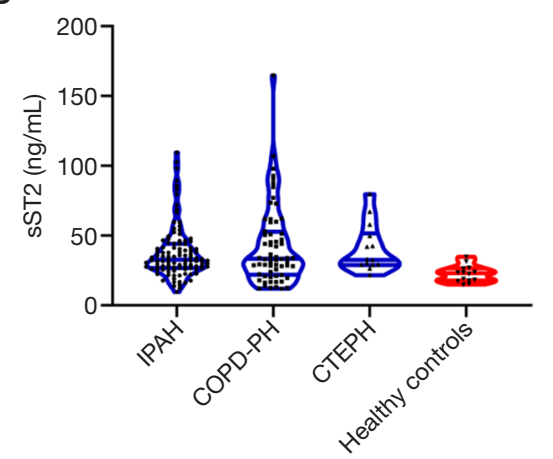

D

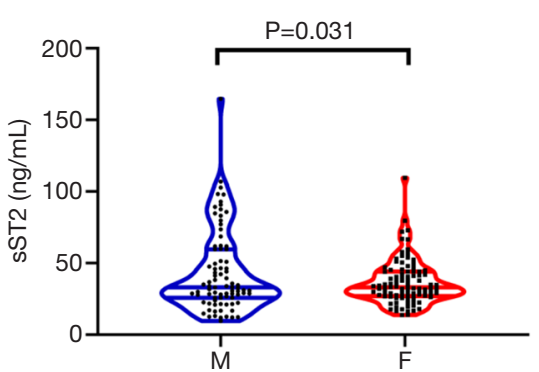

F

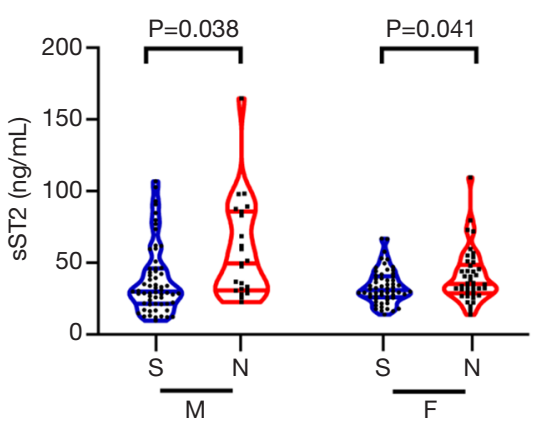

$\mathrm{H}$

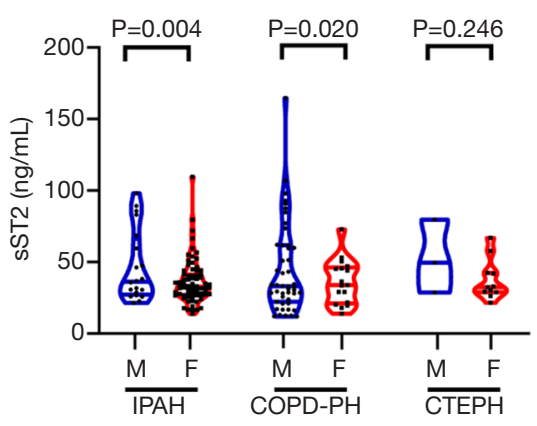

Figure 1 Concentrations of sST2 in different groups. (A) sST2 level for all patients with PH ( $\mathrm{n}=184)$ and that for healthy controls (n=14). (B) sST2 level for patients with IPAH ( $n=106)$, COPD-PH ( $n=64)$, CTEPH ( $n=14)$ and that for healthy controls $(n=14)$. (C) The concentrations of sST2 for non-survivors and those for survivors with PH. (D) The sST2 concentrations for male patients and female patients. (E) The concentrations of sST2 for male patients and for female patients in both survival group and non-survival group. (F) The sST2 levels for both male and female non-survivors and for both male and female survivors. (G) The concentrations of sST2 for non-survivors and for survivors with respective IPAH, COPD-PH and CTEPH. (H) The sST2 level for male and female patients with respective IPAH, COPD-PH and CTEPH. Abbreviations: F, Female; M, Male; N, Non-survivors; S, Survivors. 
(IQR 26.6-46.3) $\mathrm{ng} / \mathrm{mL}$ in patients with $\mathrm{PH}$. Figure $1 \mathrm{~A}$ demonstrated the different sST2 levels between all patients with $\mathrm{PH}$ and healthy controls. Figure $1 B$ demonstrated the different sST2 levels in various subgroups of $\mathrm{PH}$. As it is shown, the sST2 level in subgroups of IPAH, COPD$\mathrm{PH}$ and CTEPH was significantly higher than that in the healthy controls $(\mathrm{P}<0.05)$. However, there as no significant difference in sST2 level among $\mathrm{PH}$ subgroups. On the other hand, the concentrations of sST2 in survivors $(n=119)$ were significantly lower than that in non-survivors $(\mathrm{n}=65)$ [30.2 (IQR, 24.0-42.5) ng/mL vs. 36.8 (IQR, 30.4-55.9) $\mathrm{ng} / \mathrm{mL}$, respectively, $\mathrm{P}=0.024$ ] (Figure $1 C$ ). We also found a lower concentration of sST2 in female patients than that in male counterparts [33.0 (IQR, 26.9-44.0) $\mathrm{ng} / \mathrm{mL}$ versus 33.1 (IQR, 25.7-59.6) ng/mL, respectively, $\mathrm{P}=0.031$ ] (Figure 1D). Moreover, for both survival group and non-survival group, males showed a higher level of sST2, and for both male and female groups, a higher level of sST2 was detected for non-survivors (Figure 1E,F). Considering the subgroups with different $\mathrm{PH}$ classifications, the non-survivors and male subjects showed a much higher sST2 level $(\mathrm{P}<0.001)$ in IPAH and COPD-PH subgroups (Figure 1G,H).

\section{Relationship between sST2 and baseline characteristics}

The relationship between sST2 and baseline characteristic was illustrated in Figure S1. As shown in spearman correlation analysis, there was a weak negative correlation between sST2 with 6MWD $(\mathrm{R}=-0.286, \mathrm{P}<0.001), \mathrm{SvO}_{2}$ $(\mathrm{R}=-0.220, \mathrm{P}=0.002)$ and $\mathrm{PaO}_{2}(\mathrm{R}=-0.197, \mathrm{P}=0.049)$. However, sST2 showed a positive correlation with WHOFC $(\mathrm{R}=0.222, \mathrm{P}=0.004)$ and NT-proBNP $(\mathrm{R}=0.301$, $\mathrm{P}=0.001$ ) in all patients (Figure $\mathrm{S} 1 \mathrm{~A}$ ). In addition, according to the correlation analysis of subgroups, sST2 showed a slight negative correlation with 6MWD, CO and $\mathrm{SvO}_{2}$, but a moderate positive correlation with NT-proBNP in IPAH group (all $\mathrm{P}<0.05$ ) (Figure $\mathrm{S} 1 \mathrm{~B})$. Moreover, the level of sST2 was slightly negatively correlated with $6 \mathrm{MWD}$ but slightly positively correlated with NT-proBNP in COPD$\mathrm{PH}$ group (all $\mathrm{P}<0.05$ ) (Figure $\mathrm{S} 1 \mathrm{C}$ ). In addition, there was a more severe between SST2 and CO. However, a severe positive correlation was found between SST2 level and NTproBNP in CTEPH group (all $\mathrm{P}<0.05$ ) (Figure $\mathrm{S} 1 \mathrm{D}$ ).

\section{sST2, $\mathrm{SvO}_{2}$ and NT-proBNP are independent prognostic factors in $\mathrm{PH}$}

We also conducted the univariate and multivariate analysis
(Figure 2). In univariate analysis, factors such as age, WHOFC, 6MWD, mRAP, mPAP, PVR, CO, $\mathrm{SvO}_{2}, \mathrm{PaO}_{2}$, TAPSE, NT-proBNP and sST2 all had an effect on survivals for all patients. Therefore, considering age, sex and BSA, we used the multivariable analysis, it is revealed that both $\mathrm{sST} 2$, $\mathrm{SvO}_{2}$ and NT-proBNP were significantly associated with the primary endpoint. ( $\mathrm{HR}=1.011,95 \% \mathrm{CI}: 1.001-1.021$, $\mathrm{P}=0.028, \mathrm{HR}=0.941,95 \%$ CI: $0.917-0.965, \mathrm{P}<0.001$ and HR $=1.001,95 \%$ CI: $1.000-1.001 ; \mathrm{P}<0.001$ respectively). On the other hand, in univariate analysis, factors such as 6MWD, mPAWP, CO, PVR, $\mathrm{SvO}_{2}$, TAPSE, sST2 and NT-proBNP level were correlated with survival rate for patients with IPAH. Moreover, factors as gender, WHO-FC, 6MWD, mPAWP, CO, PVR, $\mathrm{SvO}_{2}$, sST2, and NT-proBNP were correlated with survivals for patients with COPD-PH. Unfortunately, no significant association was found between sST2 and the primary endpoint in multivariate analysis of IPAH and COPD subgroups (Figure S2).

\section{sST2 is a potential biomarker for predicting death in $\mathrm{PH}$}

ROC analysis was conducted for evaluating the sensitivity and specificity of sST2, $\mathrm{SvO}_{2}$ and NT-proBNP as predictors of non-survivors (Table 2, Figure 3). Specifically, sST2 showed an area of 0.649 under the curve as a predictor of death (95\% CI: $0.568-0.730 ; \mathrm{P}=0.001)$. The ROC-optimal sST2 cut-off value was $30.35 \mathrm{ng} / \mathrm{mL}$ with a sensitivity and specificity of $76.9 \%$ and $51.3 \%$ respectively. In addition, $\mathrm{SvO}_{2}$ could also be a predictor of death, with the initial cutoff value of $60.9 \%$ for death prediction, and the sensitivity and the specificity of $34.4 \%$ and $75.0 \%$ respectively (AUC: 0.760, 95\% CI: $0.686-0.833 ; \mathrm{P}<0.001)$. The AUC of NTproBNP was 0.798 (95\% CI: 0.706-0.891; $\mathrm{P}<0.001$ ), and the cut-off value was $458.5 \mathrm{pg} / \mathrm{mL}$ with a sensitivity and specificity of $92.9 \%$ and $61.2 \%$ respectively. More important, we performed ROC analysis on the combination of sST2 and $\mathrm{SvO}_{2}\left(\mathrm{sST} 2 \& \mathrm{SvO}_{2}\right)$, and the results showed that the AUC of the combination of the two parameters was greater than that of the single parameter analysis and sST2 \& NT-proBNP (AUC: 0.820, 95\% CI: 0.757-0.884; $\mathrm{P}<0.001$ ), and the sensitivity and the specificity of $76.6 \%$ and $78.8 \%$, respectively.

\section{The poor prognosis can be related with the sST2 elevation and $\mathrm{SvO}_{2}$ reduction}

During an average follow-up of 44.9 [IQR 28.5-64.4] months, 65 patients $(35.3 \%)$ died. the cardiovascular 


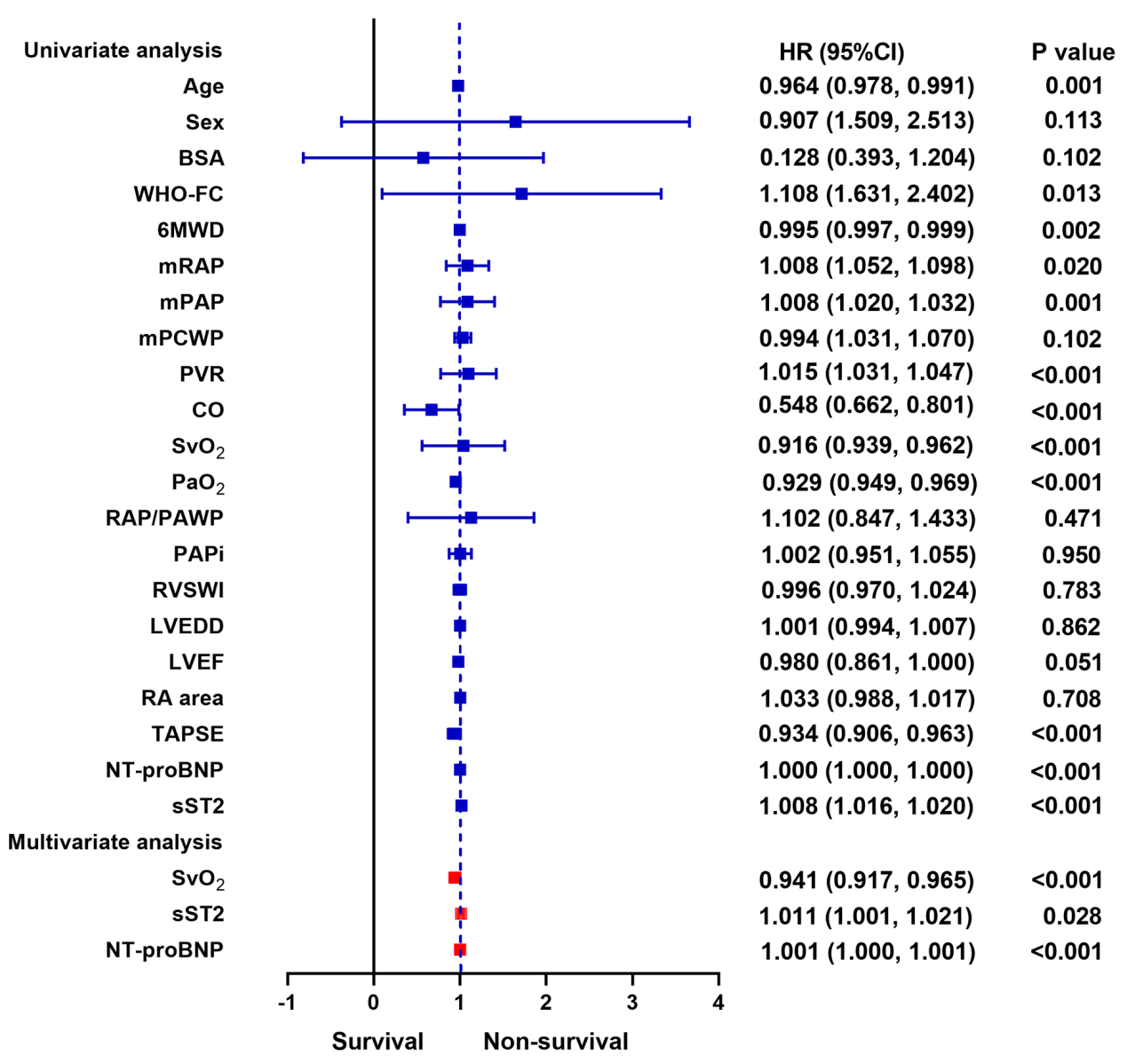

Figure 2 Forest plot showing the univariate and multivariate analysis in patients with PH.

Table 2 Areas under curve and cut-off values of independent predictors for patients with PH

\begin{tabular}{lcccccc}
\hline Variables & Cut-off value & Sensitivity & Specificity & AUC & 95\% Cl & P value \\
\hline sST2 $(\mathrm{ng} / \mathrm{mL})$ & 30.4 & 0.769 & 0.513 & 0.649 & $0.568-0.730$ & 0.001 \\
$\mathrm{SvO}_{2}(\%)$ & 60.9 & 0.344 & 0.750 & 0.760 & $0.686-0.833$ & 0.001 \\
NT-proBNP $(\mathrm{pg} / \mathrm{mL})$ & 458.5 & 0.929 & 0.612 & 0.798 & $0.706-0.891$ & $0.697-0.898$ \\
sST2\&NT-proBNP & 0.124 & 0.929 & 0.612 & 0.798 & 0.001 & $<0.001$ \\
sST2\&SvO $_{2}$ & 0.385 & 0.766 & 0.788 & 0.820 & $<0.884$ & $<01$ \\
\hline
\end{tabular}

$\mathrm{AUC}$, area under curve; sST2, soluble suppression of tumorigenicity-2; $\mathrm{SvO}_{2}$, mixed venous oxygen saturation.

mortality occurred in 41 patients $(63.1 \%)$, the respiratory failure and other causes occurred in 24 patients (36.9\%). The relevance of both sST2 and $\mathrm{SvO}_{2}$ cut-off levels on survival rate was analyzed by Kaplan-Meier curve analysis in group of $\mathrm{PH}$ and its subgroups of IPAH and COPD-PH (Figure S3A,B). During the follow-up, for all subjects with $\mathrm{PH}$, the death rate of patients with high level of sST2 $(\geq 30.4 \mathrm{ng} / \mathrm{mL})$ was approximately $46.3 \%$ (50/108), which was significantly higher than that of patients with low level of sST2 (15/76). However, the patients with sST2 concentration $<30.4 \mathrm{ng} / \mathrm{mL}(\mathrm{Log}$ rank $\mathrm{P}<0.001)$ and $\mathrm{SvO}_{2} \geq 60.9 \%(\log$ rank $\mathrm{P}<0.001)$ 
showed a much higher survival rate $(87.0 \%)$. Similarly, in subgroups of IPAH and COPD-PH, elevated sST2 $\geq 30.4$ $\mathrm{ng} / \mathrm{mL}$ and $\mathrm{SvO}_{2}<60.9 \%$ also predicted a poor prognosis of the present patients (Figure S3A,B). In addition, patients with sST2 level $\geq 30.4 \mathrm{ng} / \mathrm{mL}$ and $\mathrm{SvO}_{2}<60.9 \%$ demonstrated the lowest survival rate ( $\log$ rank $\mathrm{P}<0.05)$, no matter they were in subgroups of IPAH, COPD-PH

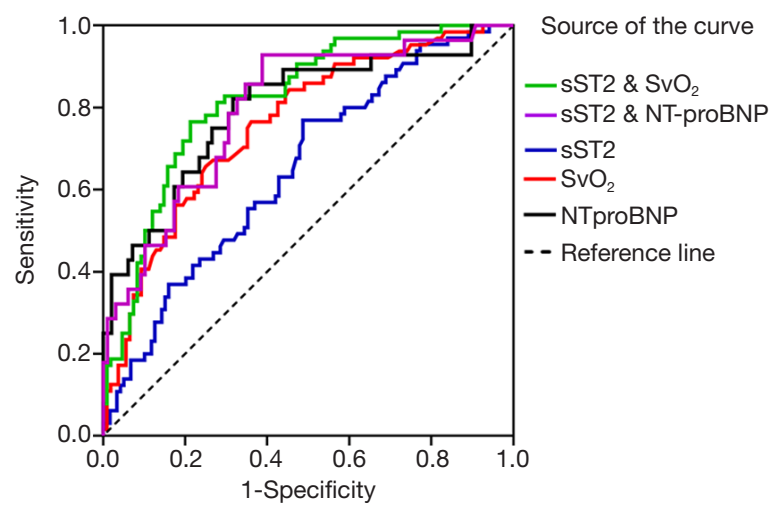

Figure 3 Receiver operating characteristics of $\mathrm{sST} 2, \mathrm{SvO}_{2}$ and NT-proBNP in patients with $\mathrm{PH}$. or in group PH (Figure 4).

\section{Discussion}

This study studied the relationship between sST2 and different hemodynamic parameters, evaluated the value of sST2 in predicting the prognosis of patients with $\mathrm{PH}$. Actually, higher level of sST2 can be detected for PH patients, non-survivors and males than that for healthy controls, survivors and females. In addition, we also found that the sST2 and NT-proBNP elevation and $\mathrm{SvO}_{2}$ reduction can predict a poor prognosis for the present patients with $\mathrm{PH}$, since a worse prognosis has been seen for patients with higher level of sST2 and lower $\mathrm{SvO}_{2}$, compared with those with a lower level of sST2 or higher $\mathrm{SvO}_{2}$ or both. And we found that the prognosis prediction of $\mathrm{sST} 2 \& \mathrm{SvO}_{2}$ was better than that of NT-proBNP or sST2\&NT-proNP in this cohort.

In 2019, Geenen et al. measured sST2 level in 104 samples from $\mathrm{PH}$ patients with different etiologies, it is shown that a higher sST2 level was associated with the more sever $\mathrm{PH}$, suggesting the value of sST2 level in the prognostic prediction for adults with PH (22). Actually,
Al

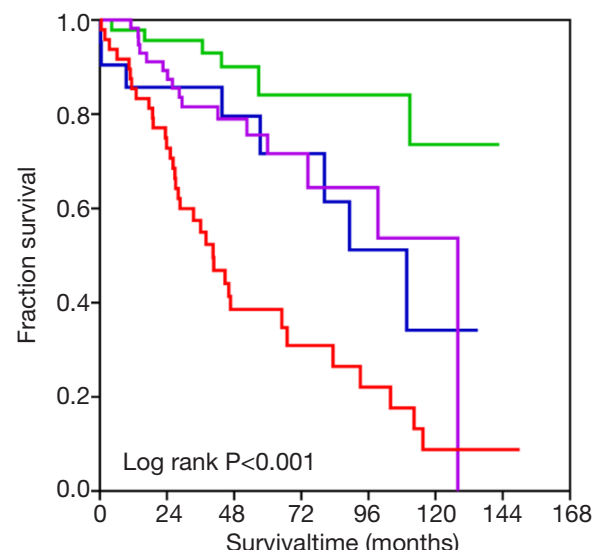

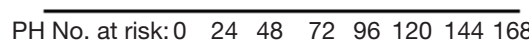

$\begin{array}{llllllll}-48 & 35 & 21 & 19 & 17 & 14 & 14 & 14\end{array}$

$\begin{array}{llllllll}-57 & 51 & 46 & 44 & 43 & 42 & 41 & 41\end{array}$

$\begin{array}{llllllll}-21 & 18 & 17 & 16 & 14 & 13 & 13 & 13\end{array}$

$\begin{array}{llllllll}-58 & 56 & 54 & 53 & 53 & 52 & 52 & 52\end{array}$
A2

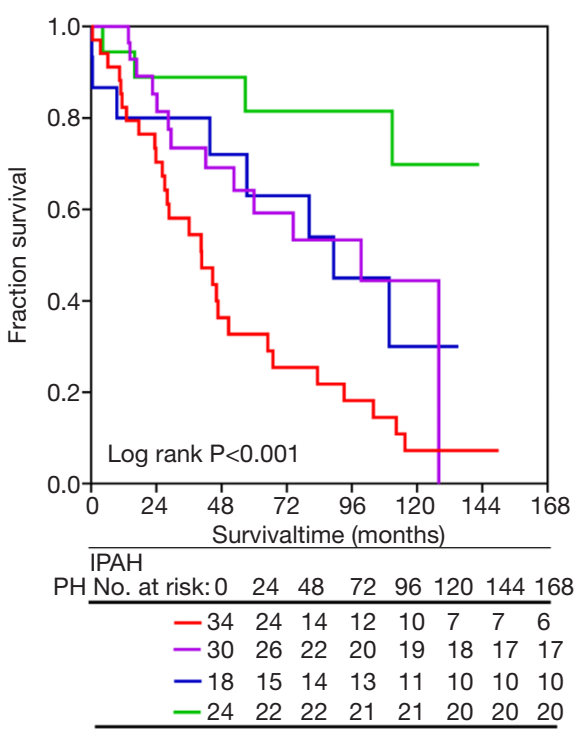

A3

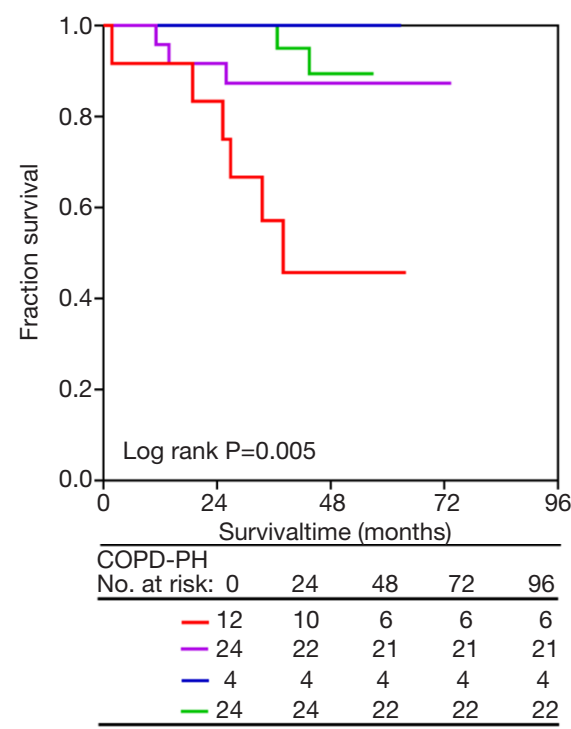

— sST2 $\geq 30.4 \mathrm{ng} / \mathrm{mL}$ and Svo $2<60.9 \%$

- sST2 $\geq 30.4 \mathrm{ng} / \mathrm{mL}$ and Svo $2 \geq 60.9 \%$

— sST2 <30.4 ng/mL and Svo $2<60.9 \%$

- sST2 $\geq 30.4 \mathrm{ng} / \mathrm{mL}$ and Svo $2 \geq 60.9 \%$

Figure $4 \mathrm{sST} 2$ combined with $\mathrm{SvO}_{2}$ estimate of survival in patients with PH. (A1-A3) sST2 $\geq 30.4 \mathrm{ng} / \mathrm{mL}$ and $\mathrm{SvO} 2<60.9 \%$ with sST2 $\geq 30.4 \mathrm{ng} / \mathrm{mL}$ and $\mathrm{SvO}_{2} \geq 60.9 \%, \mathrm{sST} 2<30.4 \mathrm{ng} / \mathrm{mL}$ and $\mathrm{SvO}_{2}<60.9 \%, \mathrm{sST} 2<30.4 \mathrm{ng} / \mathrm{mL}$ and $\mathrm{SvO}_{2} \geq 60.9 \%$ in patients with $\mathrm{PH}$, IPAH and COPD-PH. 
the median level of sST2 in this study was similar to that in our study (34.5 versus $33.1 \mathrm{ng} / \mathrm{mL}$ ). Furthermore, another study also indicated a significant association between sST2 level and worse clinical prognosis for 43 patients with various types of $\mathrm{PH}$ except $\mathrm{PH}$ induced by left heart disease. This study also found that a higher level of sST2 was detected for patients suffering from the heart failure or the non-survivors during a follow-up (23). This is in accordance with the results from our study, which demonstrated a significant association between sST2 level and the primary endpoint in a large number of patients with a longer follow-up duration. Recently, the risk stratification for PAH severity was updated at the 6th World Symposium on Pulmonary Hypertension (WSPH) which emphasized the importance of WHO-FC, 6MWD, NT-proBNP, RAP and $\mathrm{SvO}_{2}$ as risk factors for PAH (24). In our study, we found that SST2 could correlate with $6 \mathrm{MWD}$, NT-proBNP and $\mathrm{SvO}_{2} \cdot \mathrm{SvO}_{2}$, a parameter related to oxygen delivery and oxygen consumption, was also hypothesized to be a robust indicator of right ventricular function. It provides important prognostic information in many subsets of $\mathrm{PH}$ (25-27). Furthermore, more importantly, the combination of a higher level of sST2 and a lower level of $\mathrm{SvO}_{2}$ can be a useful factor to predict a poor clinical outcome in patients with $\mathrm{PH}$.

A previous study has shown that the cardiac protective effects of IL-33/ST2L ligand complex could be abolished by the blockage from sST2 (28) and a meta-analysis concluded that $\mathrm{SST} 2$ could predict poor outcomes and mortality in $\mathrm{PH}$ (29). This is consistent with our results. In addition, we also conducted statistical analysis on SST2 levels in patients with different classifications of $\mathrm{PH}$, so as to further obtain its guiding significance for prognosis in patients with IPAH and COPD-PH. In our study, the concentration of sST2 was significantly higher for non-survivors or male patients compared with that for survivors or female patients respectively. Furthermore, sST2 was associated with $\mathrm{S}_{\mathrm{V}} \mathrm{O}_{2}$ and NT-proBNP, suggesting that patients with more severe $\mathrm{PH}$ can have more possibility for an ongoing myocardial and an endothelial cell damage induced by a higher release of sST2. Unfortunately, the exact reasons for a higher level of sST2 in patients of $\mathrm{PH}$ or male patients have not been known. Further research is needed to elucidate the pathophysiologic involvement of sST2 in $\mathrm{PH}$ and to explore whether the sST2 secretion is affected by sex differences.

According to our study, patients with a higher sST2 level showed a worse prognosis than the counterparts with a lower sST2 level. Therefore, the sST2 level could be used for risk stratification for patients with $\mathrm{PH}$. In addition, in comparison to NT-proBNP, sST2 has a narrower biological variation (30), which is an advantage for the repeated measurements of a biomarker. Therefore, besides measuring the NT-proBNP level, a measurement of sST2 level could be considered to predict the prognosis for the patients with PH. Our study showed the high sST2 level in different classification of $\mathrm{PH}$. It would also be interesting to investigate the effects of $\mathrm{PH}$ treatment on sST2 level at different time intervals, as this may elucidate whether sST2 could be used as a biomarker for assessing the treatment effectiveness. Therefore, further studies on the changes of sST2 level for patients with $\mathrm{PH}$ during their treatments will be of greater clinical significance.

In addition, there are several limitations in our studies. Firstly, considering the disparity in the dialysis practice for patients from different regions and effects from the introduction of new treatment modalities, the results obtained from this single-center study should be validated in a larger group of subjects from different regions. Secondly, we were unable to perform the serial assessments of sST2 level, so, whether the sST2 level could be used to evaluate the therapeutic effects was not yet clear. Thirdly, we were unable to measure the level of ligand IL-33, which may offer additional mechanistic insights into our observed correlation between sST2 and PH severity. Finally, based on existing clinical data and blood samples, there may have been selection bias in our study, but our results were not significantly different after adjustment for the three disease types, so we considered these results acceptable.

\section{Conclusions}

The levels of sST2 were higher in patients with PH. Higher sST2 was independently associated with increased mortality, as well as lower $\mathrm{SvO}_{2}$ in patients with $\mathrm{PH}$. Especially, the combination of higher sST2 and lower $\mathrm{SvO}_{2}$ had the strongest predictive value of mortality in patients with $\mathrm{PH}$. This may give clinicians more ways to assess a prognosis of patients.

\section{Acknowledgments}

Funding: This study was supported by the Program of National Natural Science Foundation of China (81870042, 81700045 and 81900050), National Science and Technology Information System of the People's Republic of China (2018YFC1313603), the program of Shanghai Pulmonary 
Hospital (FKLY20005), and Program of Natural Science Foundation of Shanghai (18ZR1431500).

\section{Footnote}

Reporting Checklist: The authors have completed the STROBE reporting checklist. Available at http://dx.doi. org/10.21037/jtd-20-2732

Data Sharing Statement: Available at http://dx.doi. org/10.21037/jtd-20-2732

Conflicts of Interest: All authors have completed the ICMJE uniform disclosure form (available at http://dx.doi. org/10.21037/jtd-20-2732). The authors have no conflicts of interest to declare.

Ethical Statement: The authors are accountable for all aspects of the work in ensuring that questions related to the accuracy or integrity of any part of the work are appropriately investigated and resolved. This study conformed to the provisions of the Declaration of Helsinki (as revised in 2013). Also, it was approved by the Ethics committees of Shanghai Pulmonary Hospital (K20-195Y). All patients have submitted informed consents.

Open Access Statement: This is an Open Access article distributed in accordance with the Creative Commons Attribution-NonCommercial-NoDerivs 4.0 International License (CC BY-NC-ND 4.0), which permits the noncommercial replication and distribution of the article with the strict proviso that no changes or edits are made and the original work is properly cited (including links to both the formal publication through the relevant DOI and the license). See: https://creativecommons.org/licenses/by-nc-nd/4.0/.

\section{References}

1. Vonk-Noordegraaf A, Haddad F, Chin KM, et al. Right heart adaptation to pulmonary arterial hypertension: physiology and pathobiology. J Am Coll Cardiol 2013;62:D22-33.

2. Galiè N, Humbert M, Vachiery JL, et al. 2015 ESC/ERS Guidelines for the diagnosis and treatment of pulmonary hypertension: The Joint Task Force for the Diagnosis and Treatment of Pulmonary Hypertension of the European Society of Cardiology (ESC) and the European Respiratory Society (ERS): Endorsed by: Association for
European Paediatric and Congenital Cardiology (AEPC), International Society for Heart and Lung Transplantation (ISHLT). Eur Heart J 2016;37:67-119.

3. Simonneau G, Montani D, Celermajer DS, et al. Haemodynamic definitions and updated clinical classification of pulmonary hypertension. Eur Respir J 2019;53:1801913.

4. Farber HW, Miller DP, Poms AD, et al. Five-Year outcomes of patients enrolled in the REVEAL Registry. Chest 2015;148:1043-54.

5. Galiè N, Humbert M, Vachiery JL, et al. 2015 ESC/ERS Guidelines for the Diagnosis and Treatment of Pulmonary Hypertension. Rev Esp Cardiol (Engl Ed) 2016;69:177.

6. Hoeper MM, Kramer T, Pan Z, et al. Mortality in pulmonary arterial hypertension: prediction by the 2015 European pulmonary hypertension guidelines risk stratification model. Eur Respir J 2017;50:1700740.

7. Thenappan T, Shah SJ, Rich S, et al. Survival in pulmonary arterial hypertension: a reappraisal of the NIH risk stratification equation. Eur Respir J 2010;35:1079-87.

8. Thenappan T, Glassner C, Gomberg-Maitland M. Validation of the pulmonary hypertension connection equation for survival prediction in pulmonary arterial hypertension. Chest 2012;141:642-50.

9. Nagaya N, Nishikimi T, Uematsu M, et al. Plasma brain natriuretic peptide as a prognostic indicator in patients with primary pulmonary hypertension. Circulation 2000;102:865-70.

10. Nagaya N, Uematsu M, Satoh T, et al. Serum uric acid levels correlate with the severity and the mortality of primary pulmonary hypertension. Am J Respir Crit Care Med 1999;160:487-92.

11. Renard S, Paulin R, Breuils-Bonnet S, et al. Pim-1: A new biomarker in pulmonary arterial hypertension. Pulm Circ 2013;3:74-81.

12. Santos M, Reis A, Goncalves F, et al. Adiponectin levels are elevated in patients with pulmonary arterial hypertension. Clin Cardiol 2014;37:21-5.

13. Kakkar R, Hei H, Dobner S, et al. Interleukin 33 as a mechanically responsive cytokine secreted by living cells. J Biol Chem 2012;287:6941-8.

14. Schmitz J, Owyang A, Oldham E, et al. IL-33, an interleukin-1-like cytokine that signals via the IL-1 receptor-related protein ST2 and induces T helper type 2-associated cytokines. Immunity 2005;23:479-90.

15. Pascual-Figal DA, Januzzi JL. The biology of ST2: the International ST2 Consensus Panel. Am J Cardiol 2015;115:3B-7B. 
16. Villacorta H, Maisel AS. Soluble ST2 Testing: A Promising Biomarker in the Management of Heart Failure. Arq Bras Cardiol 2016;106:145-52.

17. Aimo A, Vergaro G, Ripoli A, et al. Meta-Analysis of Soluble Suppression of Tumorigenicity-2 and Prognosis in Acute Heart Failure. JACC Heart Fail 2017;5:287-96.

18. Aimo A, Vergaro G, Passino C, et al. Prognostic Value of Soluble Suppression of Tumorigenicity-2 in Chronic Heart Failure: A Meta-Analysis. JACC Heart Fail 2017;5:280-6.

19. Shao D, Perros F, Caramori G, et al. Nuclear IL-33 regulates soluble ST2 receptor and IL-6 expression in primary human arterial endothelial cells and is decreased in idiopathic pulmonary arterial hypertension. Biochem Biophys Res Commun 2014;451:8-14.

20. Carlomagno G, Messalli G, Melillo RM, et al. Serum soluble ST2 and interleukin-33 levels in patients with pulmonary arterial hypertension. Int $\mathrm{J}$ Cardiol 2013;168:1545-7.

21. Leuchte HH, Baezner C, Baumgartner RA, et al. Residual pulmonary vasodilative reserve predicts outcome in idiopathic pulmonary hypertension. Heart 2015;101:972-6.

22. Geenen LW, Baggen VJM, Kauling RM, et al. The Prognostic Value of Soluble ST2 in Adults with Pulmonary Hypertension. J Clin Med 2019;8:1517.

23. Plácido R, Cortez-Dias N, Robalo Martins S, et al. Prognostic stratification in pulmonary hypertension: A multi-biomarker approach. Rev Port Cardiol

Cite this article as: Sun $\mathrm{Y}$, Wang L, Meng $\mathrm{X}$, Gong S, Zhao Q, Shi L, Jiang R, He J, Wu W, Li Y, Luo C, Qiu H, Li J, Yuan P, Liu J. Soluble ST2 and mixed venous oxygen saturation for prediction of mortality in patients with pulmonary hypertension. J Thorac Dis 2021;13(6):3478-3488. doi: 10.21037/ jtd-20-2732
2017;36:111-25.

24. Galiè N, Channick RN, Frantz RP, et al. Risk stratification and medical therapy of pulmonary arterial hypertension. Eur Respir J 2019;53:1801889.

25. Sitbon O, Humbert M, Nunes H, et al. Long-term intravenous epoprostenol infusion in primary pulmonary hypertension: prognostic factors and survival. J Am Coll Cardiol 2002;40:780-8.

26. McLaughlin VV, Sitbon O, Badesch DB, et al. Survival with first-line bosentan in patients with primary pulmonary hypertension. Eur Respir J 2005;25:244-9.

27. Sitbon O, McLaughlin VV, Badesch DB, et al. Survival in patients with class III idiopathic pulmonary arterial hypertension treated with first line oral bosentan compared with an historical cohort of patients started on intravenous epoprostenol. Thorax 2005;60:1025-30.

28. Sanada S, Hakuno D, Higgins LJ, et al. IL-33 and ST2 comprise a critical biomechanically induced and cardioprotective signaling system. J Clin Invest 2007;117:1538-49.

29. Luk KS, Ip C, Gong MQ, et al. A meta-analysis of soluble suppression of tumorigenicity 2 (sST2) and clinical outcomes in pulmonary hypertension. J Geriatr Cardiol 2017;14:766-71.

30. Wu AH, Wians F, Jaffe A. Biological variation of galectin-3 and soluble ST2 for chronic heart failure: implication on interpretation of test results. Am Heart J 2013;165:995-9. 
A

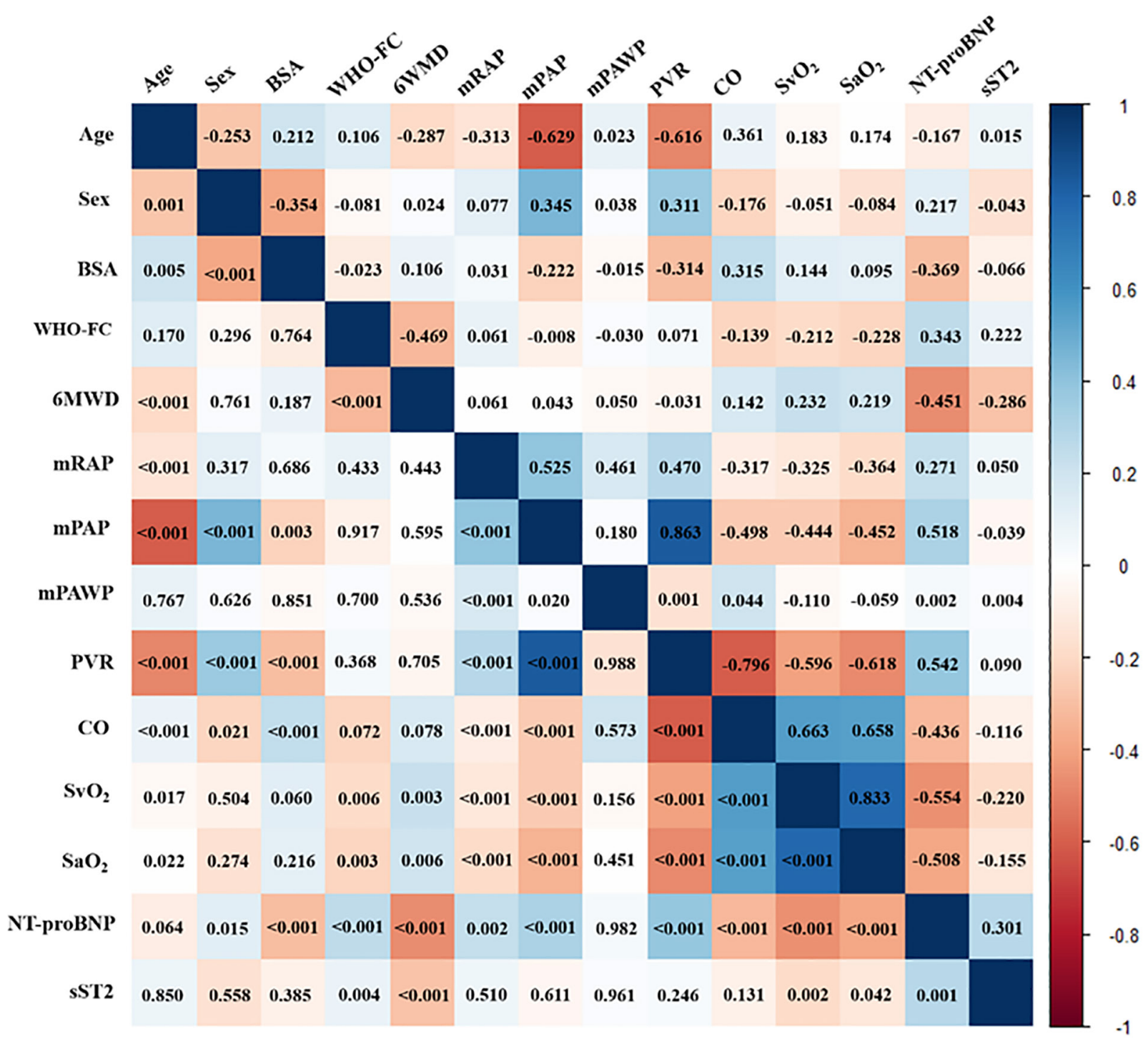

BI

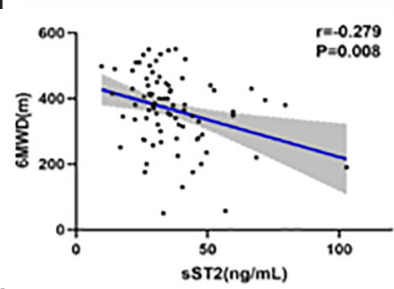

CI

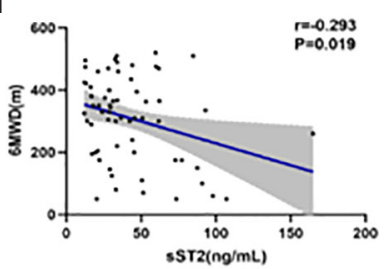

DI

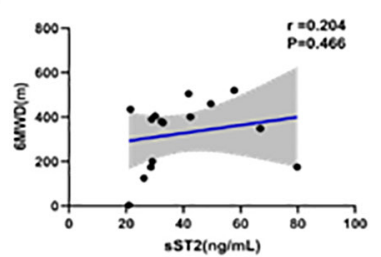

B2

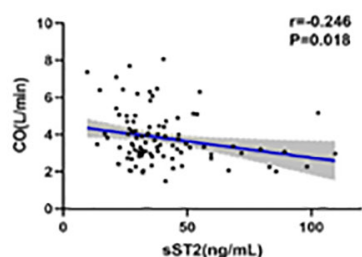

C2

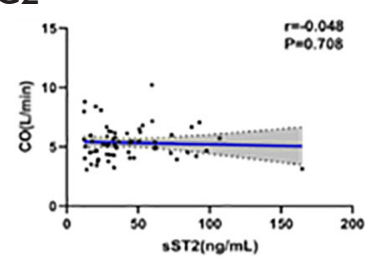

D2

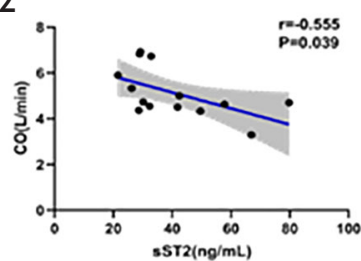

B3

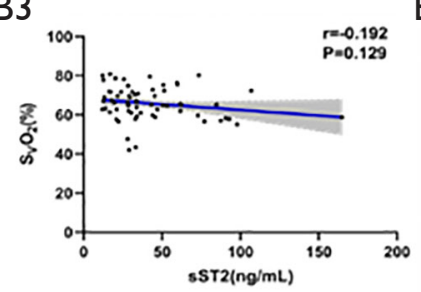

C3

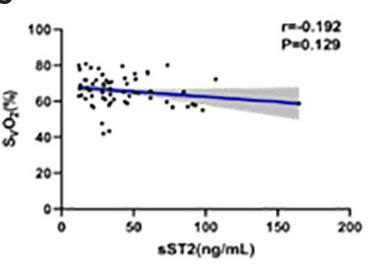

C4
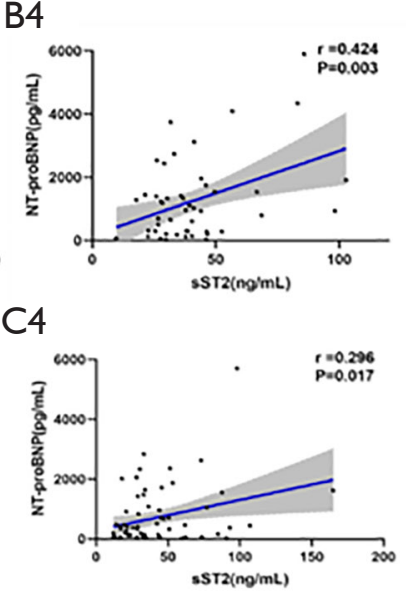

D4

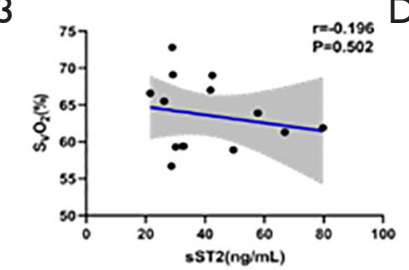

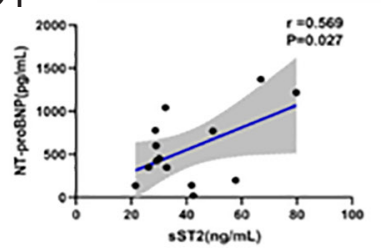

Figure S1 The relationship between sST2 and baseline characteristic. (A) The relationship between sST2 and baseline characteristicsin PH (P value in the bottom left, $\mathrm{r}$ value in the top right). (B1-4) the relationship between sST2 and $6 \mathrm{MWD}, \mathrm{CO}, \mathrm{S}_{\mathrm{V}} \mathrm{O}_{2}$ and NT-proBNP in IPAH. (C1-4) the relationship between sST2 and 6MWD, CO, $\mathrm{S}_{\mathrm{V}} \mathrm{O}_{2}$ and NT-proBNP in COPD-PH. (D1-4) the relationship between sST2 and $6 \mathrm{MWD}, \mathrm{CO}, \mathrm{S}_{\mathrm{V}} \mathrm{O}_{2}$ and NT-proBNP in CTEPH. 
A

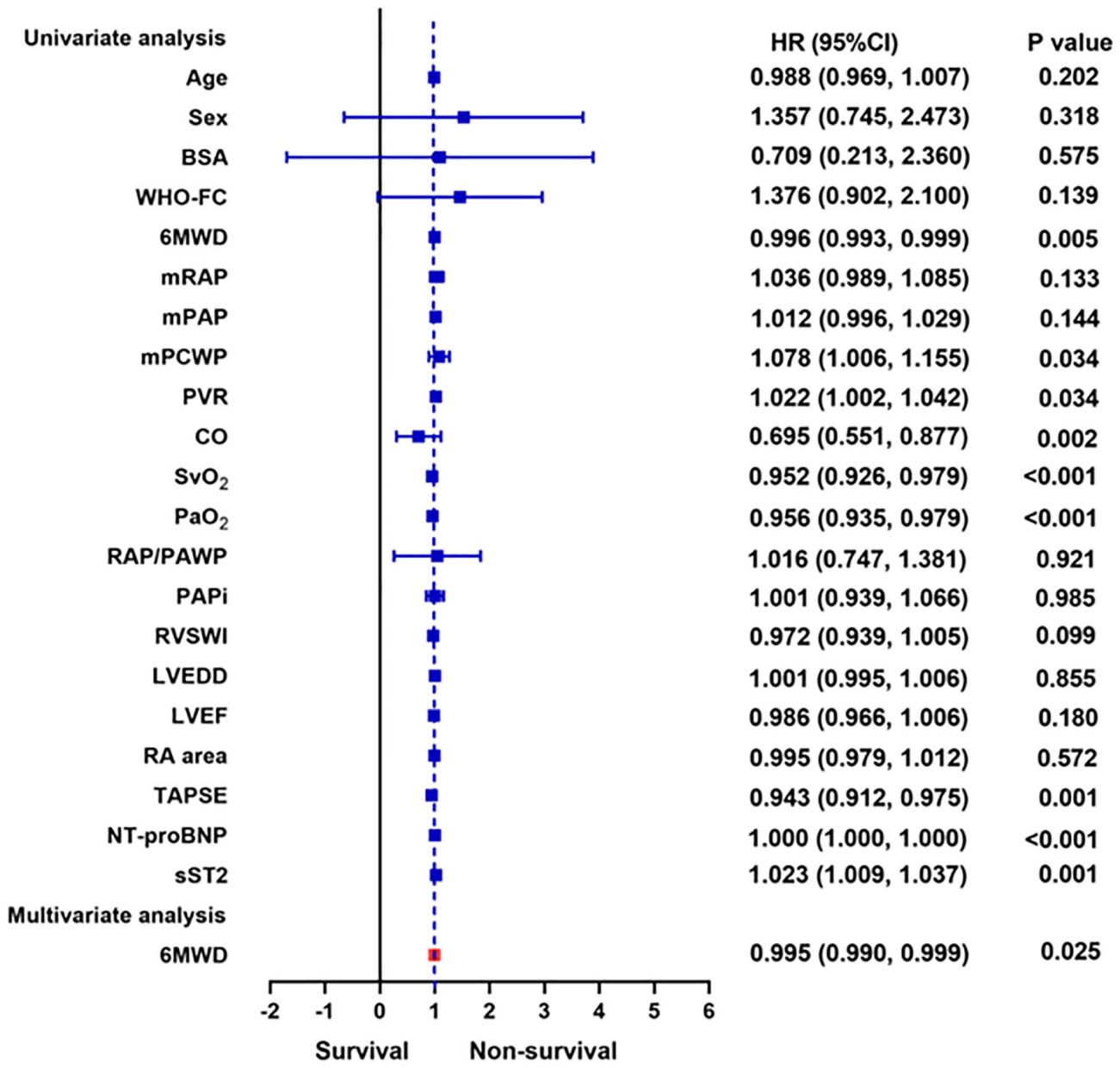

B

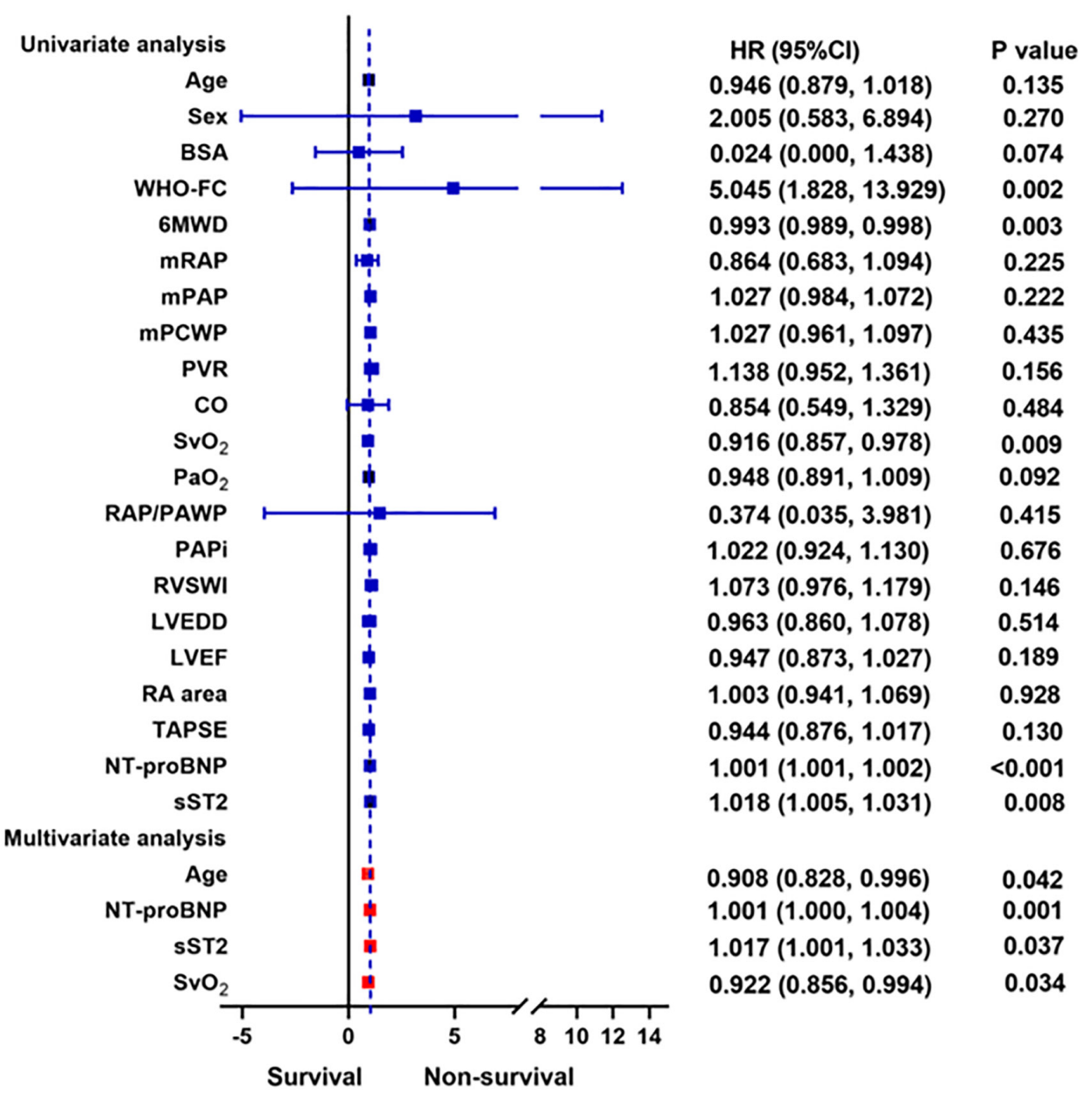

Figure S2 Forest plot showing the univariate and multivariate analysis in patients with IPAH and COPD-PH. (A) Forest plot showing the univariate and multivariate analysis in patients with IPAH. (B) Forest plot showing the univariate and multivariate analysis in patients with COPD-PH. 
Al

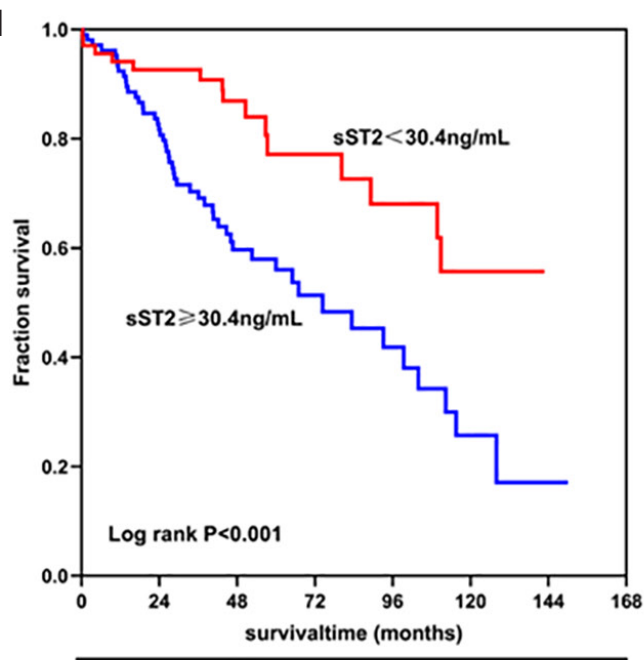

\begin{tabular}{llllllll}
\hline PH No. at risk: 0 & 24 & 48 & 72 & 96 & 120 & 144 & 168 \\
\hline
\end{tabular} $\begin{array}{lllllllll}- & 76 & 71 & 68 & 65 & 63 & 61 & 61 & 58\end{array}$

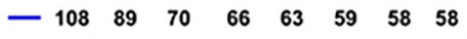

A2

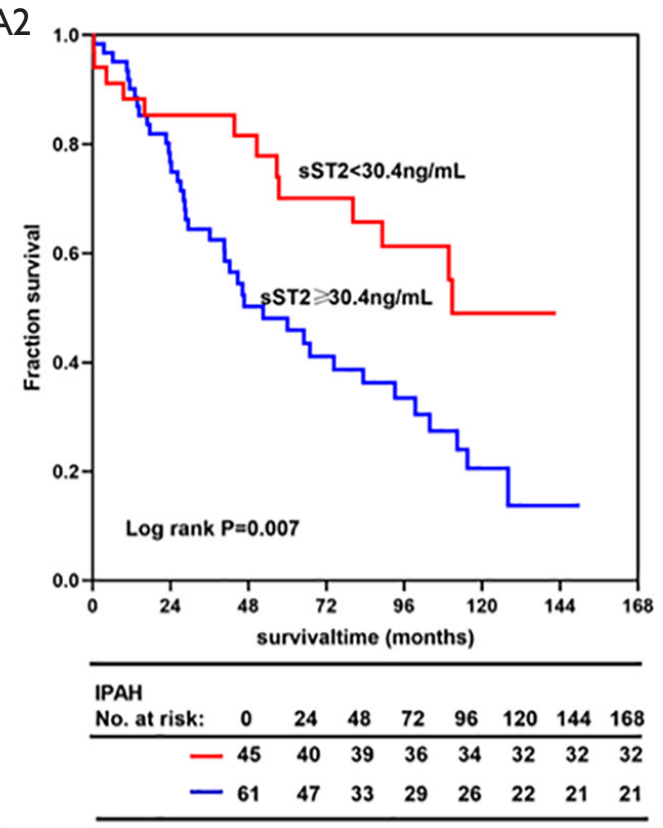

A3

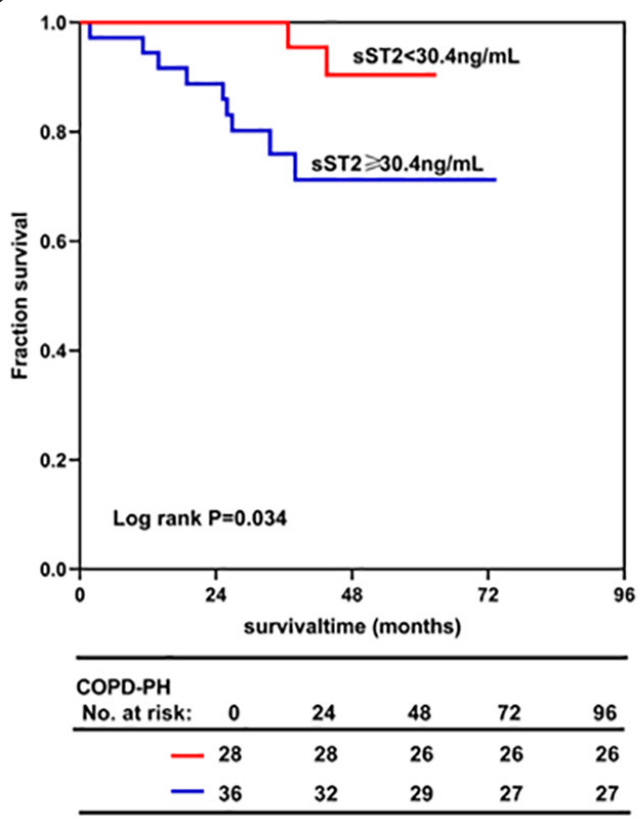

BI

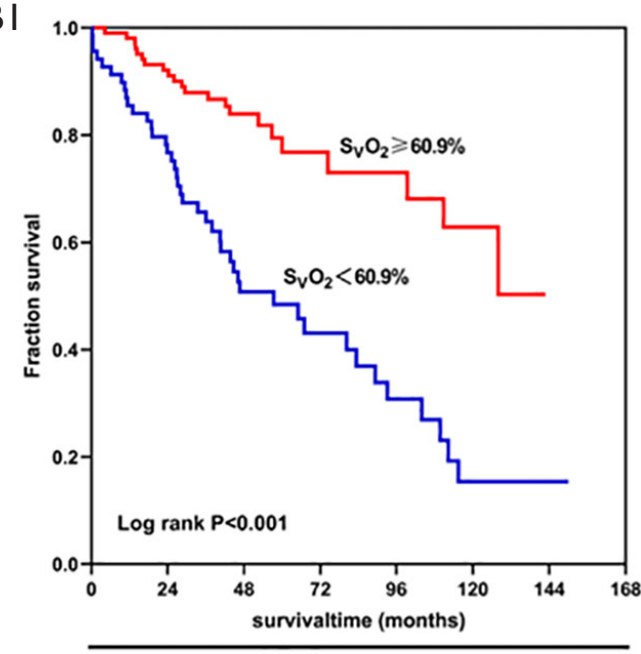

\begin{tabular}{llllllll}
\hline PH No. at risk: 0 & 24 & 48 & 72 & 96 & 120 & 144 & 168 \\
\hline
\end{tabular} $\begin{array}{lllllllll}-103 & 95 & 90 & 85 & 84 & 82 & 80 & 80\end{array}$ \begin{tabular}{rrrrrrrr}
$-\quad 81$ & 65 & 50 & 47 & 43 & 39 & 39 & 39 \\
\hline
\end{tabular}

B2

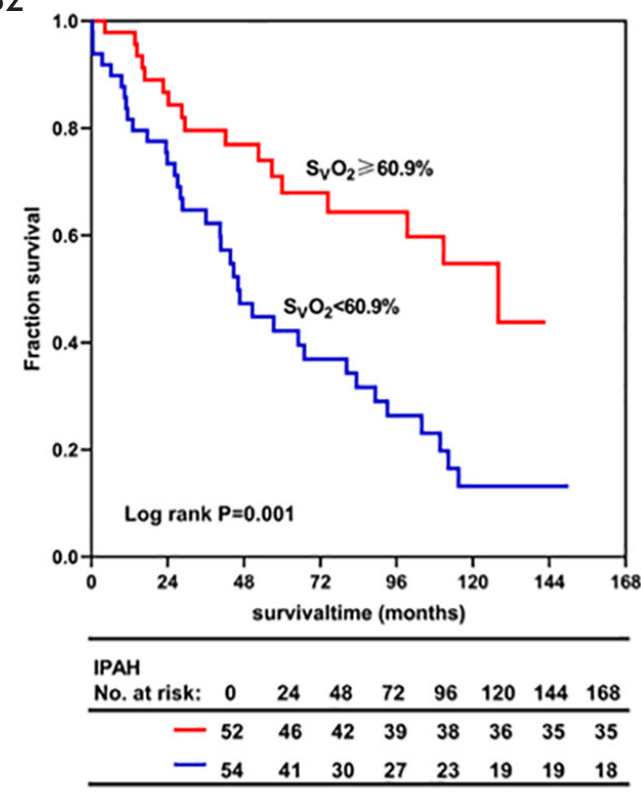

B3

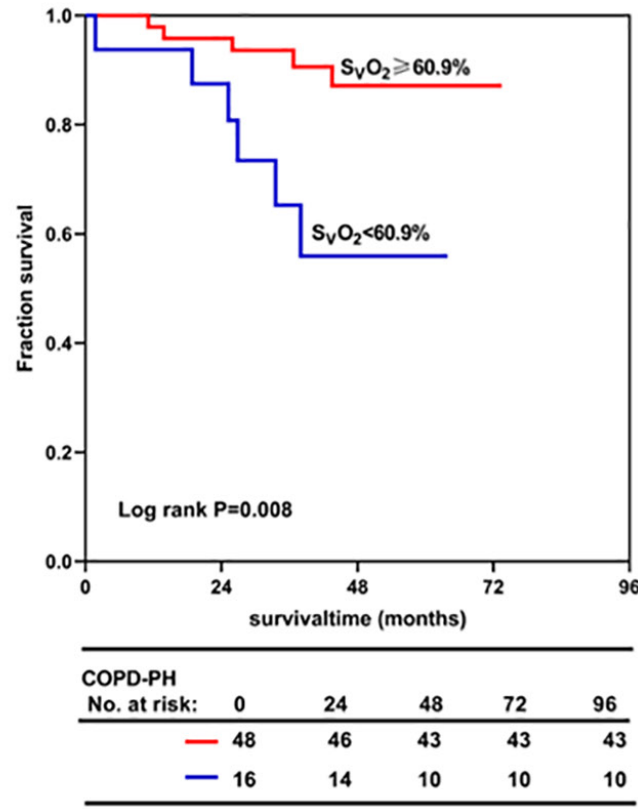

Figure S3 Kaplan-Meier estimates of survival in patients with PH. (A1-A3) sST2 $<30.4 \mathrm{ng} / \mathrm{mL}$ with sST2 $\geq 30.4 \mathrm{ng} / \mathrm{mL}$ in patients with PH, IPAH and COPD-PH. (B1-B3) $\mathrm{SvO}_{2}<60.9 \%$ with $\mathrm{SvO}_{2} \geq 60.9 \%$ in patients with PH, IPAH and COPD-PH. 